\title{
A Novel Approach to Fabricate Carbon Nanomaterials-Nanoparticle Solids through Aqueous Solutions and Their Applications
}

\author{
Hammad Younes $^{1,2} \cdot$ Haiping Hong ${ }^{1}$ (1) $\cdot$ G. P. Peterson ${ }^{3}$
}

Received: 4 November 2020 / Revised: 14 December 2020 / Accepted: 17 December 2020 / Published online: 20 March 2021

(c) The Author(s) 2021

\begin{abstract}
A better understanding of the bonding and aggregation processes occurring between carbon nanomaterials and metal oxide particles in aqueous solutions is important in the development of novel nanosolids for applications in the areas of sensor development, highly conductive paint, nanotube alignment, polymer composites, Li-ion batteries, and many other areas. The current investigation reviews these processes and presents a detailed description of the aggregation processes occurring between carbon nanomaterials and metal oxide particles (metals) in various aqueous solutions. The results indicate that the charge attraction between the particles results in a strong homogeneous bonding that occurs within the aqueous solution and for the first time demonstrate and describe the aggregation process of these nanoparticles. The relative importance of many parameters that impact the aggregation process is identified and discussed, and guidelines for controlling the aggregation process are presented. This is a simple and cost-effective process to manufacture a novel nano-solid based on carbon nanomaterial and metal oxide. In addition, the process is easy to scale up and optimize. The methodology could lead to many significant applications as well as commercialization.
\end{abstract}

Keywords Nanosolid $\cdot$ Aggregation technique $\cdot$ Nanofluids $\cdot$ Charge attraction $\cdot$ Nanoparticles $\cdot$ Nanomanufacturing

\section{Introduction}

Carbon nanomaterials and metal oxide nanoparticles have attracted significant consideration for the last two decades because of their attractive mechanical, electrical, and thermophysical properties. For example, carbon nanotubes (CNTs) have a thermal conductivity (TC) of $3000 \mathrm{~W} / \mathrm{mK}$ $[1,2]$, an electrical conductivity of more than $4000 \mathrm{~S} / \mathrm{cm}$ [3],

Haiping Hong

haiping.hong@sdsmt.edu

Hammad Younes

hammad.younes@ku.ac.ae

G. P. Peterson

bud.peterson@gatech.edu

1 Department of Electrical Engineering, South Dakota School of Mines and Technology, South Dakota, Rapid City 57701, USA

2 Department of Mechanical Engineering, Khalifa University of Science and Technology, Masdar Institute, PO Box 54224, Abu Dhabi, UAE

3 Woodruff School of Mechanical Engineering, Georgia Institute of Technology, Atlanta, GA 30332, USA a tensile modulus of $1 \mathrm{TPa}$, and a tensile strength of 50-150 $\mathrm{GPa}[4,5]$. As a result, these nanomaterials have been applied in several applications with the purpose of improving the overall system performance. To further develop nanocomposites with improved properties, such as the electrical and TC, CNTs have been mixed with different types of polymers. Historically, epoxies have been mixed with CNTs to improve the mechanical and thermophysical characteristics of the composite. Tensile strength and Young's modulus of the resulting new material have demonstrated an improvement as high as $34 \%$ and $60 \%$, respectively [6]. The results obtained by Paiva et al. [7] showed that Young's modulus of SWNT/poly(vinyl alcohol) (PVA) composite has improved by $55 \%$ when only $5 \mathrm{wt} \%$ of functionalized SWNTs has been used to fabricate the composite. Also, an increase in the tensile modulus of more than $130 \%$ for MWNTs/PVA composites at values as low as $2 \mathrm{wt} \%$ nanotube loading has been reported [8]. Similarly, CNTs, CNFs, graphene, and metal oxide NPs have been used to prepare nanofluids, a fluid containing well-dispersed nanoparticles, in an attempt to create fluids with high TC $[9,10]$. The resulting highly conductive nanofluids can be used in numerous applications, for example in cooling purposes in heat transfer equipment 
such as nuclear reactors, radiators, vehicles, and electronics applications. Several investigations have been conducted in the past several years designed to evaluate the fabrication of highly conductive nanofluids with very high TC properties [11-13]. One of the early examples of nanofluid fabrication has been reported by Hong et al. [14], in which $0.05 \mathrm{wt} \%$ CNTs was shown to increase the TC of the fluid by $10 \%$.

A review of the recent research conducted using CNTs and metal oxide NPs to enhance the mechanical, thermal, and electrical properties of composites and the TC of nanofluids indicates only modest improvement in the thermophysical and mechanical properties for many cases. For example, for most nanofluids, the TC improvement is not significant enough for practical uses. The concomitant rise in viscosity of the fluids results in a poor dispersion because of the use of high weight percentages of CNTs or NPs and is the principal constraint limiting the practical implementation of nanofluids in thermal management applications [15]. For the case of nanocomposites, the dispersion issue and lack of alignment were the principal impediments to the enhancement of the mechanical and the electrical/thermal properties [16]. As a result, the scientific community has tried to identify other solutions by which the mechanical, electrical, and thermophysical properties can be improved at low weight percentages, without increasing the viscosity of the fluids. A number of different approaches have been pursued; one of the most common is the alignment of CNTs or nanoparticles in aqueous solutions to enhance nanofluids' TC. However, this approach is only applicable for magnetically sensitive nanomaterials. A limited number of metal-oxide nanoparticles such as $\mathrm{Fe}_{2} \mathrm{O}_{3}, \mathrm{Fe}_{3} \mathrm{O}_{4}, \mathrm{NiFe}_{2} \mathrm{O}_{4}, \mathrm{CoFe}_{2} \mathrm{O}_{4}$, etc. $\mathrm{Fe}_{2} \mathrm{O}_{3}$ and $\mathrm{CuO}$ have been evaluated for the nanofluids' TC enhancement. Furthermore, the impact of alignment on the TC of nanofluids has also been investigated. A $0.4 \mathrm{vol} \%$ of $\mathrm{Fe}_{2} \mathrm{O}_{3}$ NPs was found to increase the TC of water by $20 \%$, while $\mathrm{CuO}$ NPs improved the TC by only $12 \%$. By applying an external magnetic field to align the NPs, the TC could be increased by $83 \%$. This significant improvement is attributed to the improved alignment of the $\mathrm{Fe}_{2} \mathrm{O}_{3}$ nanoparticles [17]. Although the alignment of magnetic metal oxide nanoparticles in aqueous solutions is relatively easy, the alignment of carbon nanomaterials such as CNTs, CNFs, and graphene is more complicated, as they do not typically possess magnetic properties. An interesting solution for this problem was first introduced by Hong et al. [18] in which SWNT's alignment in water was achieved by attaching $\mathrm{Fe}_{2} \mathrm{O}_{3}$ NPs to the SWNTs by using sodium dodecylbenzene sulfonate (NaDDBS) surfactant as binder and then applying a magnetic field. In this work and in related references [19-26], it was observed that the aggregation process could be accomplished in an aqueous medium, in the presence of SDBS surfactants. The presence of SDBS is crucial to help obtain good dispersion for the CNTs and promote the attraction of the nanoparticles through the electrostatic interaction between the sulfonic head of the surfactant that has a negative charge, due to the dissociation process in water and the partially positive nanoparticles [27]. However, previous studies have focused only on the properties of fluids. As a result, all of the components (carbon nanomaterials, surfactants, and metal oxides) were in the aqueous state and could not be removed or reduced. In most circumstances, surfactants are needed, but are not helpful to the physical properties of the mixture. As a result, there is a need to develop a new method to use surfactants to fabricate uniformly aggregated solids containing carbon nanomaterials and metal oxides for applications such as composites, battery electrodes, etc., but keeping the surfactant to a minimum.

In the following investigation, a new concept for fabricating novel solids based on carbon nanomaterials and metal oxides through aqueous solutions is developed and their use in several important applications is proposed and discussed. The goal of this work is to gain a comprehensive grasp of the bonding and aggregation processes that occur between CNMs and metal-oxide nanoparticles.

\section{Investigative Approach}

Graphene was purchased from Cheap Tubes Inc. and NaDDBS and $\mathrm{Fe}_{2} \mathrm{O}_{3}$ nanoparticles were purchased from SigmaAldrich and used as received. Ultrasonication was performed with a Branson Model 450 Digital Sonifier with a 1/2" disrupter horn. Scanning electron microscopy (SEM) images were obtained using a Zeiss Supra40 variable-pressure field emission SEM with an Oxford AZtecEnergy advanced system. Transmission electron microscopy (TEM) images were obtained using a JEOL JEM-2100 LaB6 transmission electron microscope equipped with a high-resolution (HR)-style objective-lens pole piece.

The manufacturing process is shown in Fig. 1. Briefly, SDBS was mixed with CNTs and dispersed in deionized water using ultrasonication. Then the nanoparticles were added into the mixture and dispersed again. After this, vacuum filtration was used to separate the fabricated aggregated

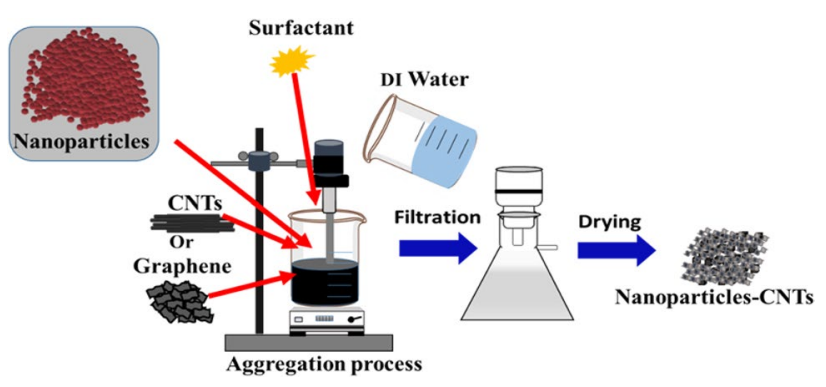

Fig. 1 Synthesis scheme for the aggregated nanoparticles (CNTs) 
solids. Finally, a vacuum oven was used to dry the aggregated solids. The solution was filtered and dried in a vacuum oven. The same procedure was followed for the fabrication of $\mathrm{Fe}_{2} \mathrm{O}_{3}$-CNTs using CNTs in the place of graphene.

\section{Concept Detail Discussion}

Several different types of nanoparticles were used to coat the carbon nanomaterials through the aggregation process. For example, $\mathrm{Fe}_{2} \mathrm{O}_{3}$ nanoparticles were aggregated on the surface of CNTs as shown in Fig. 1. This approach is not applicable in the case of non-aqueous solutions, such as epoxy, because SDBS is soluble only in aqueous solutions. Therefore, we fabricated the aggregated nanoparticle CNTs in a water solution first. Figure 2a shows an SEM image of the CNTs that were used in the aggregation process. As is shown, the CNTs are agglomerated and interconnected with each other. To better observe the CNTs, a TEM image was acquired as depicted in Fig. 2b. The TEM image indicates that the CNTs are MWNTs as the diameter of the tubes is larger than $20 \mathrm{~nm}$. The TEM image (Fig. 2c) suggests that $\mathrm{Fe}_{2} \mathrm{O}_{3}$ NPs have an average particle size between 25 and $50 \mathrm{~nm}$. Furthermore, the $\mathrm{Fe}_{2} \mathrm{O}_{3}$ crystals are shown in the figure with a hexagonal structure. Figure 2c (inset) shows the lattice fringes and the space is around $0.37 \mathrm{~nm}$. In addition, the crystallinity of the $\mathrm{Fe}_{2} \mathrm{O}_{3} \mathrm{NPs}$ is further confirmed by the diffraction pattern acquired from TEM analysis, as depicted in Fig. 2d.

The aggregation of the nanoparticles on the surface of the carbon nanomaterials is attributed to the electrostatic interaction that occurs between the nanoparticles and the surfactant. The attraction between NaDDBs surfactant and CNTs is strong because of the $\pi-\pi$ interaction between the benzene ring of the NaDDBs and the surface of the CNTs. In addition, the repulsive force between the head of the surfactant, which is the sulfonic group in the NaDDBS case, improves the deagglomeration of the CNTs [27]. As shown in Fig. 3a, the head of the NaDDBS surfactant dissociates in water into two parts, the Na cation part, and the sulfonic anionic part. The surfactant's tail that has the hydrocarbon chain and the benzene ring is adsorbed at the surface of the carbon nanotube, whereas the negatively charged sulfonic group attracts the partially positively charged iron oxide nanoparticles. The carbon nanotube solution has a $\mathrm{pH}$ equal to 6.15 at which the magnetic sensitive $\gamma-\mathrm{Fe}_{2} \mathrm{O}_{3}$ nanoparticles have a positive zeta potential charge (Fig. 3b) that interacts with the negative charge.
Fig. 2 a SEM image showing many CNTs entangled together. b High-resolution TEM image showing CNTs. c Low magnification TEM image of $\gamma-\mathrm{Fe}_{2} \mathrm{O}_{3}$ nanoparticles. d Diffraction pattern obtained from TEM analysis and it shows the crystalline properties of the $\gamma-\mathrm{Fe}_{2} \mathrm{O}_{3}$ particles [28]
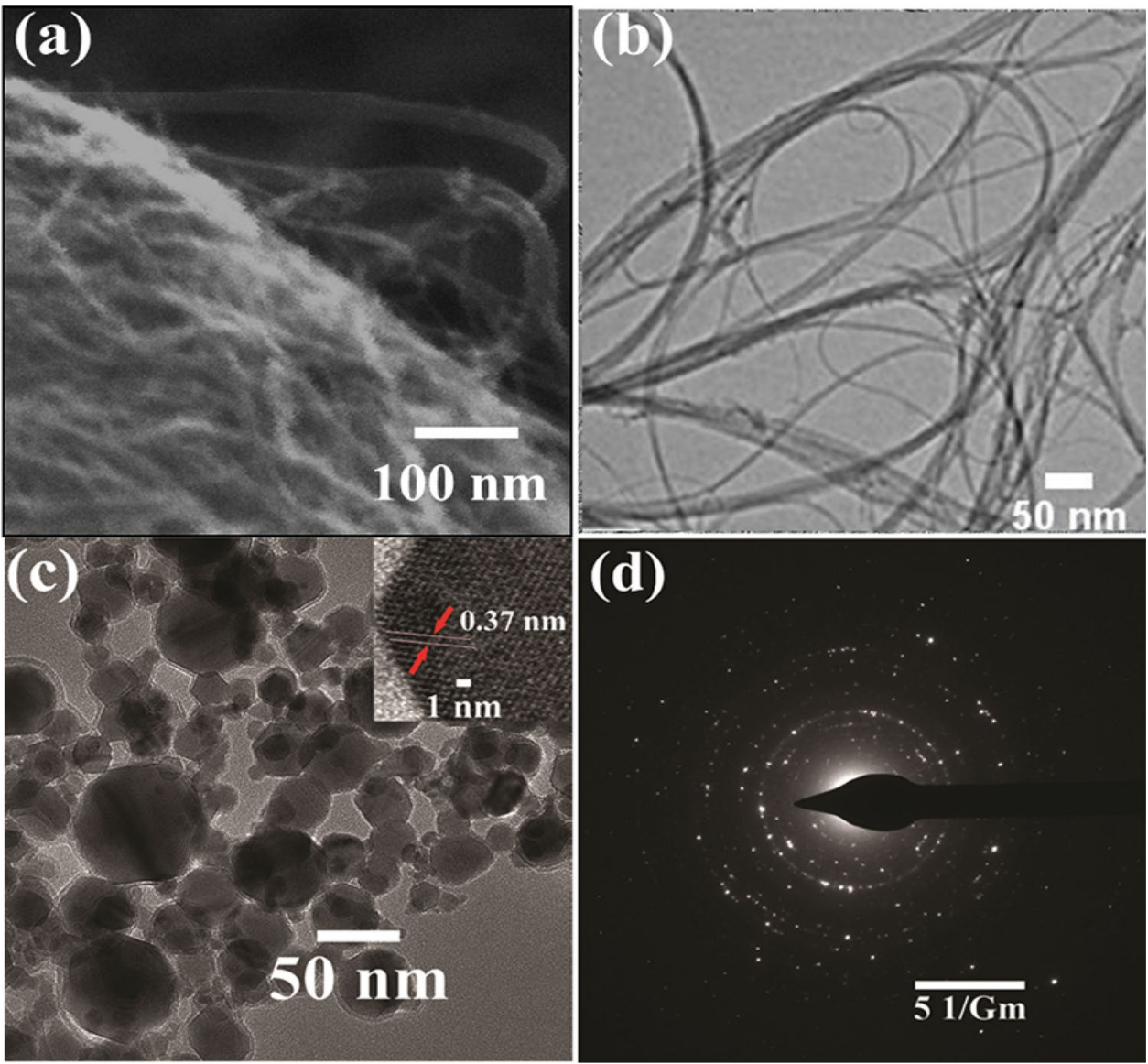


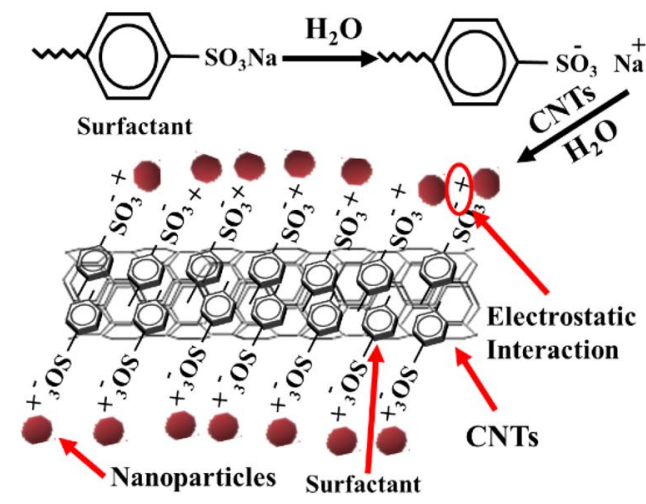

(a)

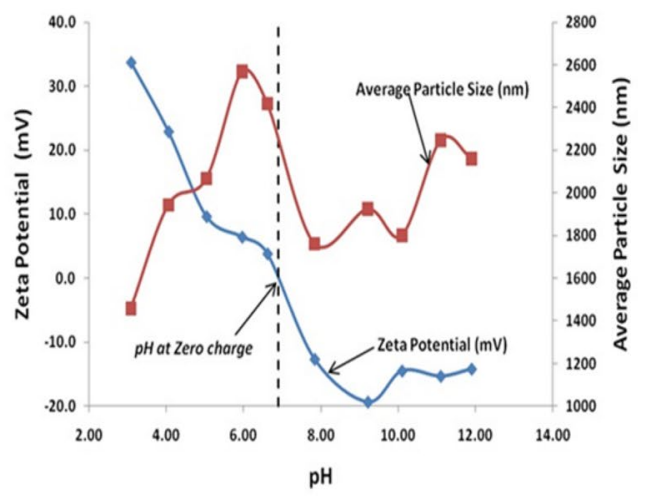

(b)

Fig. 3 a The separation reaction of NaDDBS in aqueous solution and the electrostatic interaction between nanoparticles and CNTs. b Zeta potential and average particle size vs. different $\mathrm{pH}$ values [17]

The SEM image in Fig. 4a shows the CNTs with aggregated $\mathrm{Fe}_{2} \mathrm{O}_{3}$ nanoparticles on the tube's surface. This was also observed when TEM images of the $\mathrm{MgO}$ nanoparticles were reviewed. The TEM image in Fig. $4 b$ shows the aggregations of the $\mathrm{MgO}$ nanoparticles along the carbon nanotubes. Figure $4 \mathrm{c}$ shows the thermogravimetric analysis (TGA) of the aggregated $\mathrm{Fe}_{2} \mathrm{O}_{3}$-CNTs. It is apparent here that at $100-200{ }^{\circ} \mathrm{C}$, some of the NaDDBS surfactant and other impurities have been burned off, with the vast majority of the CNTs having been burned completely at $600^{\circ} \mathrm{C}$. Moreover, the TGA analysis shows the presence of approximately $38 \% \mathrm{Fe}_{2} \mathrm{O}_{3}$ nanoparticles. Figure 4 d, showing the XPS, confirms the presence of the $\gamma-\mathrm{Fe}_{2} \mathrm{O}_{3}$ nanoparticles in the composite.

In summary, all of the images and experimental results indicate that the concept works. Carbon nanomaterials and nanoparticles can be aggregated uniformly in the nanoscale. This method could also be extended to non-carbon
Fig. 4 a SEM image showing the aggregation of $\mathrm{Fe}_{2} \mathrm{O}_{3}$ nanoparticles on carbon nanotubes. b TEM image showing the aggregation of $\mathrm{MgO}$ nanoparticles on carbon nanotubes. c Thermogravimetric analysis (TGA) of $\mathrm{Fe}_{2} \mathrm{O}_{3}$ nanoparticles aggregated on CNTs. $d$ The XPS spectrum of $\gamma-\mathrm{Fe}_{2} \mathrm{O}_{3}$ nanoparticles aggregated on CNTs. e High-resolution XPS spectrum of iron (2p) bands of the $\mathrm{Fe}_{2} \mathrm{O}_{3}$ nanoparticles aggregated on CNTs
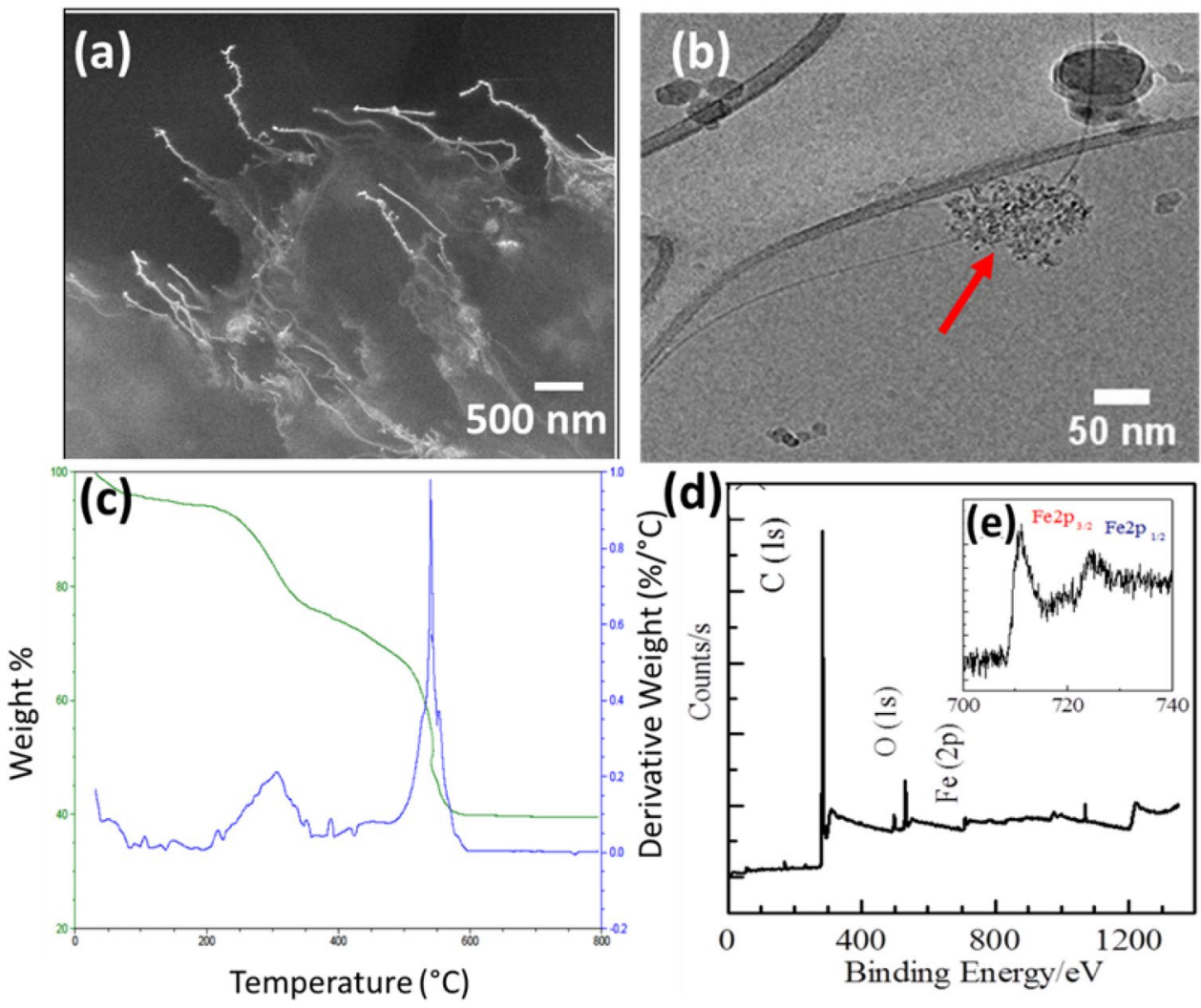
nanomaterials. The nanoparticles used could be metal oxides, but also could be comprised of elemental metals, metalloids, metal alloys, metal sulfides, metal seleniums, and/or a combination thereof. In addition, this method is simple, cost-effective, and easy to be applied in large-scale applications.

\section{Applications}

The novel carbon nanomaterials-nanoparticle solids fabricated from aqueous solutions have many applications.

\subsection{Energy Storage}

Recently, an investigation of aggregated nanoparticlesCNMs for lithium-ion battery applications was done by Christensen et al. [29]. In this study, the same aggregation concept was used to attach both $\mathrm{Fe}_{2} \mathrm{O}_{3}$ and silicon nanoparticles to different carbon nanomaterials in a uniform dispersion and attachment process. Surfactants were used along with dispersion and attachment agents. An anode was fabricated from $\mathrm{Fe}_{2} \mathrm{O}_{3}$ /graphene/surfactant. The anode demonstrated a capacity of over $1000 \mathrm{mAh} / \mathrm{g}$ with a stable charge/ discharge process of 21 cycles and evidence of relatively little capacity reduction. The Si materials exhibited an ultrahigh capacity of approximately $4000 \mathrm{mAh} / \mathrm{g}$. The ability of Si nanoparticles to attach to CNF, SWCNT, and graphene by this method is quite significant in the development of this technology. Cycling data showed a very high capacity, over
$1000 \mathrm{mAh} / \mathrm{g}$ [29]. Figure 5 is $\mathrm{SEM}$ images for (a) $\mathrm{Fe}_{2} \mathrm{O}_{3} /$ CNF/surfactant, (b) $\mathrm{Fe}_{2} \mathrm{O}_{3} / \mathrm{SWNT} /$ surfactant, (c) Si/CNF/ surfactant, and (d) Si/SWNT/surfactant.

\subsection{Magnetic Enhancement Materials}

\subsubsection{Magnetic Composites}

Magnetic composites are very important and have numerus applications, such as magnetic recording media water purifications, energy storage, and high-density data storage. Therefore, the aggregation process of magnetic nanoparticles such as $\mathrm{Fe}_{2} \mathrm{O}_{3}, \mathrm{CrO}_{2}$, or spinel structure compounds like $\mathrm{MnFe}_{2} \mathrm{O}_{4}, \mathrm{CoFe}_{2} \mathrm{O}_{4}$, and $\mathrm{NiFe}_{2} \mathrm{O}_{4}$ is also important [30-32]. The results obtained by Neupane et al. in [22] suggest that the coercive field of SWNTs coated with $\mathrm{Fe}_{2} \mathrm{O}_{3}$ nanoparticles was twice that of pristine SWNTs (Fig. 6a and b).

\subsubsection{Magnetic Sensitive Mats}

In a previous investigation, the magnetic properties of carbon nanostructure (CNS) mats were investigated. SWNTs were mixed first with surfactants and $\mathrm{Fe}_{2} \mathrm{O}_{3}$ using the aggregation process explained earlier and then dispersed with CNS using the tip sonicator. This was followed by a vacuumed filtration technique that was used to fabricate the CNS mats. A series of characterization techniques were conducted to study the effects of using $\mathrm{Fe}_{2} \mathrm{O}_{3}$ on the fabricated CNS mats. For example, XPS (Fig. 7a) has been used to confirm the presence of the $\gamma-\mathrm{Fe}_{2} \mathrm{O}_{3}$ nanoparticles in the composite,
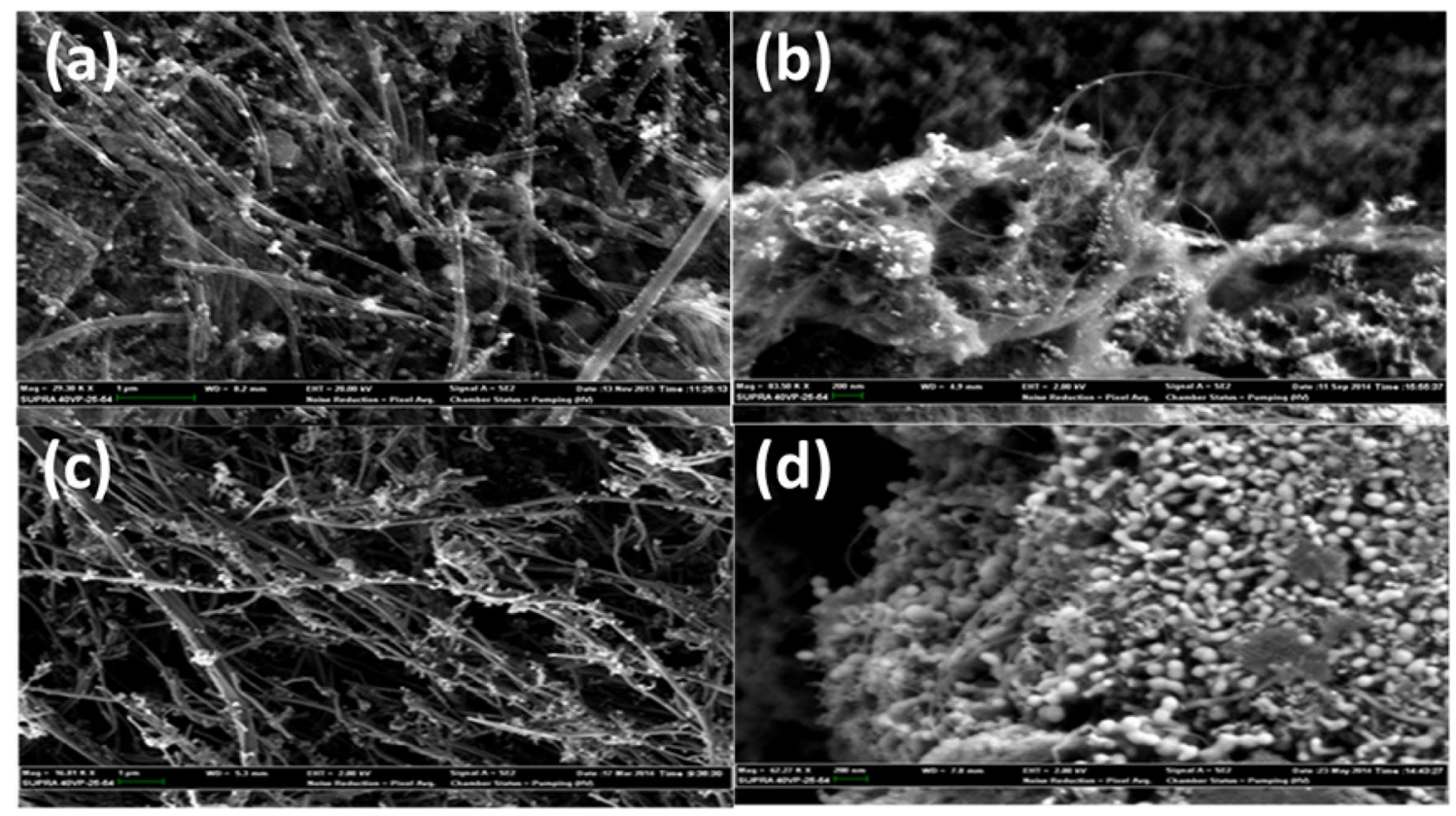

Fig. $5 \mathrm{SEM}$ images of $\mathbf{a} \mathrm{Fe}_{2} \mathrm{O}_{3} / \mathrm{CNF} /$ surfactant, $\mathbf{b ~ F e} \mathrm{O}_{3} / \mathrm{SWNT} /$ surfactant, $\mathbf{c} \mathrm{Si} / \mathrm{CNF} /$ surfactant, and d Si/SWNT/surfactant [29] 
Fig. 6 a Magnetization $(M)$ versus applied magnetic field $(H)$ for pristine SWNTs, $\mathrm{Fe}_{2} \mathrm{O}_{3}$ nanoparticles, and SWNTs coated with $\mathrm{Fe}_{2} \mathrm{O}_{3}$ nanoparticles. b Enlarged $M-H$ curves for pristine SWNTs and SWNTs coated with $\mathrm{Fe}_{2} \mathrm{O}_{3}$ nanoparticles [22]
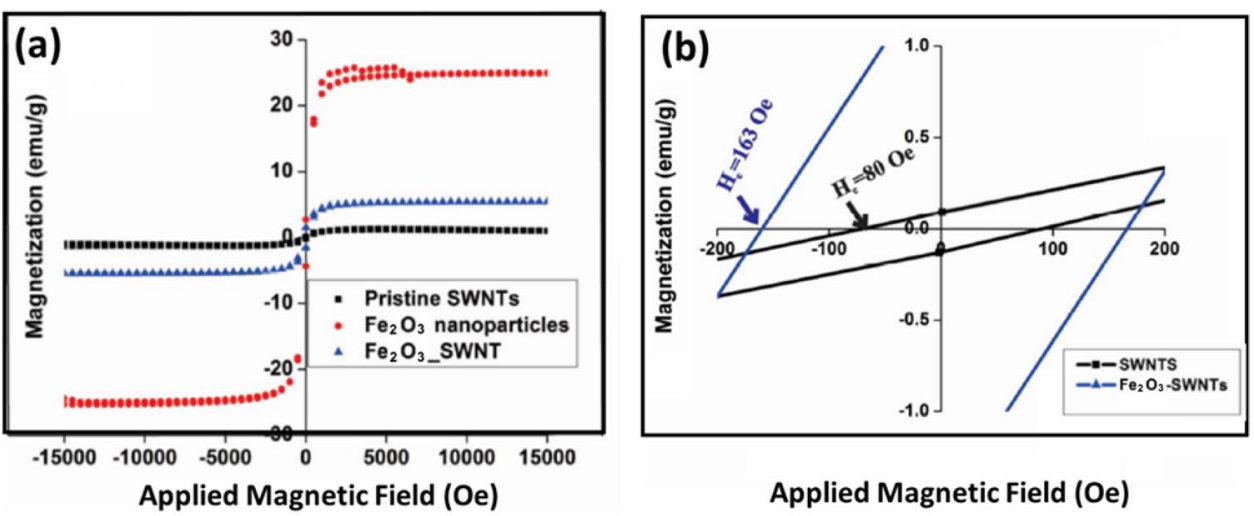

Fig. 7 a XPS for CNS- $--\mathrm{Fe}_{2} \mathrm{O}_{3}$ (inset shows high-resolution XPS spectrum of iron $2 \mathrm{p}$ bands). b Nitrogen adsorptiondesorption isotherm of $\gamma-\mathrm{Fe}_{2} \mathrm{O}_{3}$ NP-decorated CNS mats. c Raman spectra of as-fabricated CNS mat. d Magnetic properties of $\gamma$ - $\mathrm{Fe}_{2} \mathrm{O}_{3} \mathrm{NP}$-decorated CNS mats [27] (a)
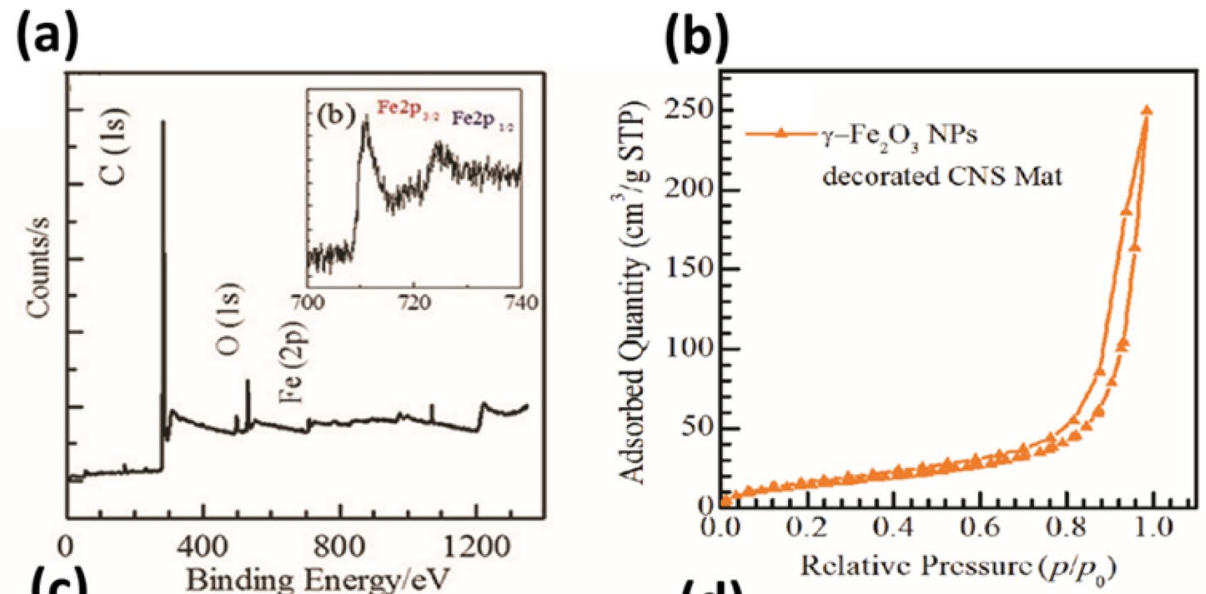

(c)

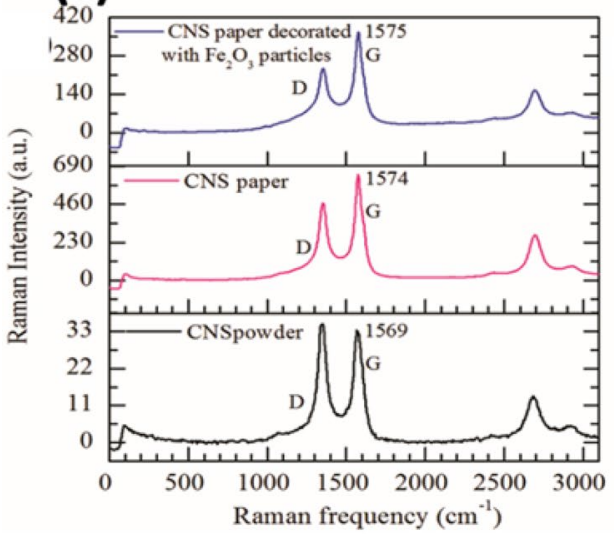

(d)

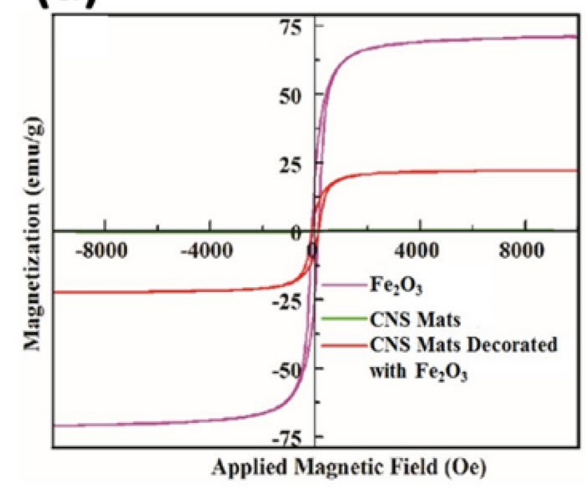

which were added to the CNTs during the fabrication process and attached at the surface of the CNT. As shown, the peaks of carbon and oxygen and characteristic iron peaks are apparent. Figure $4 \mathrm{e}$ presents a high-resolution spectrum that clearly indicates the locations of the Fe (2p3/2) and Fe $(2 \mathrm{p} 1 / 2)$ peaks at $713 \mathrm{eV}$ and $725 \mathrm{eV}$, respectively. The spectrum peaks are in agreement with the values reported for $\gamma-\mathrm{Fe}_{2} \mathrm{O}_{3}$ nanoparticles in the literature. In addition, the Brunauer-Emmett-Teller (BET) analysis was conducted to better understand the surface area of the fabricated mats (Fig. 7b). According to nitrogen adsorption and desorption measurements, the CNS mats possess low BET-specific surface areas of $55.8 \mathrm{~m}^{2} / \mathrm{g}$ and the DFT (density functional theory)-calculated total pore volume of $0.0263 \mathrm{~cm}^{3} / \mathrm{g}$.

Raman analysis illustrated in Fig. 7c indicates the existence of the two common peaks for CNTs; $G$ peak and $D$ peak, reduction in the $I D / I G$ ratio from 1.06 to 0.65 is noticed, because of washing out the impurities during the filtration process. In addition, the presence of $\mathrm{Fe}_{2} \mathrm{O}_{3}$ has decreased $I D / I G$ ratio further. Furthermore, vibratingsample magnetometer (VSM) study was done to understand more about the magnetic properties of the fabricated 
materials as shown in Fig. 7d, where the results gained from three samples, pristine carbon nanostructures (CNS) mats, CNS mat with $\gamma-\mathrm{Fe}_{2} \mathrm{O}_{3}$ and $\gamma-\mathrm{Fe}_{2} \mathrm{O}_{3}$ showed that pristine CNS mats are not magnetic. However, the aggregation of the $\gamma-\mathrm{Fe}_{2} \mathrm{O}_{3}$ NPs occurred on the CNS in creation of magnetic sensitive CNS mats. The improved magnetization of $\gamma-\mathrm{Fe}_{2} \mathrm{O}_{3}$ NPs covered CNS mats can be attributed to the large quantity of Fe present within the carbon foam. Indeed, the saturation magnetization of CNS mats is expected to increase with an increased quantity of $\gamma-\mathrm{Fe}_{2} \mathrm{O}_{3}$ nanoparticles. As a result of using the $\mathrm{Fe}_{2} \mathrm{O}_{3}$ nanoparticle aggregation approach, the electromagnetic wave absorption has been improved, as shown in Fig. 8 .

\subsection{Lubricants and Nanogrease}

Nanogrease is another important application for the aggregated nanoparticle CNTs. Several publications have appeared in recent years discussing the fabrication of nanogreases using aggregated nanoparticle CNTs with high thermal and electrical conductivity properties [33-42]. A study by Younes et al. concluded that SWNTs form a strong 3D net structure because of the strong Van der Waals forces and this is the main reason behind the creation of stable SWNT nanogrease, as shown in Fig. 9. In addition, this study demonstrated that the attachment of the iron oxide at the outer face of the CNTs prevents the formation of the 3D network structure [37]. Furthermore, the results indicate that the TC for SWNTs grease at $10 \mathrm{wt} \%$ has not changed regardless of the strength of the magnetic field or its application duration time, because of the strong Van der Waals forces between the SWNTs, which hinder movement and resist the magnetic field [43] (Fig. 10).

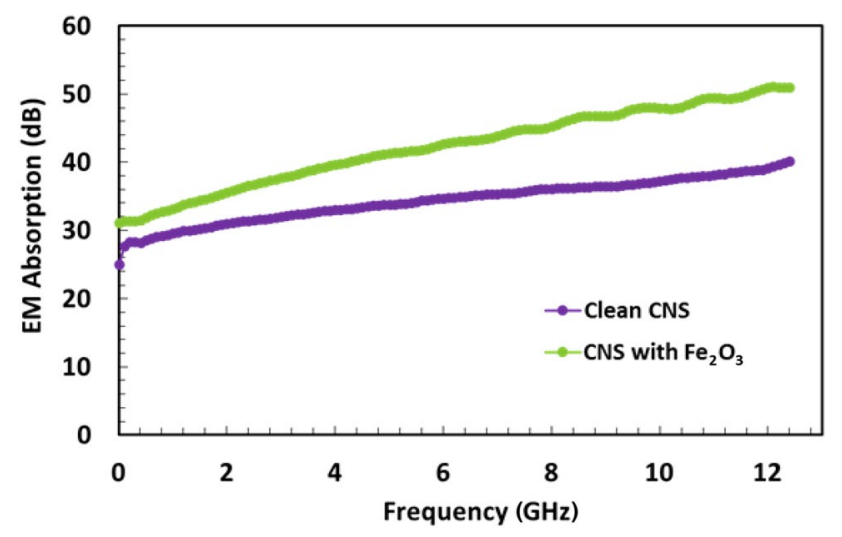

Fig. 8 Electromagnetic wave absorption of carbon nanostructures mat and aggregated $\mathrm{Fe}_{2} \mathrm{O}_{3}$ carbon nanostructures mat [28]

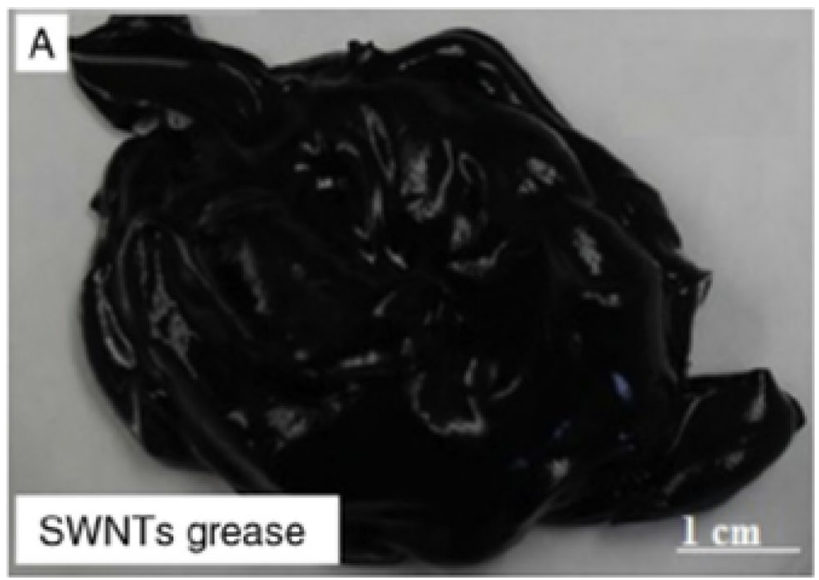

Fig. 9 Image of SWNT grease [37]

\subsection{Polymer Composites}

Recently, several authors have used the aggregated nanoparticles-CNT process to fabricate nanocomposites with improved mechanical properties and thermal and electrical conductivity. Luan et al. used aggregated $\mathrm{Fe}_{2} \mathrm{O}_{3}$-CNTs and studied $\mathrm{Fe}_{2} \mathrm{O}_{3}$-CNTs alignment's influence on the mechanical properties of PVA [21]. Liu et al. used the same technique to study the effect of the alignment on the tensile strength and TC of epoxy composite [32]. Recent work was performed by Younes et al. that reported using $\mathrm{Fe}_{2} \mathrm{O}_{3}$-CNTs to fabricate a special type of Buckypapers with magnetic properties that can be used in many applications [27, 44].

Luan et al. [21] used the aggregation approach to prepare a magnetic SWNTs PVA composite. It was found that using a pair of magnets has an obvious impact on aligning SWNTs within the composite, which ultimately improves the composite mechanical properties. A sample prepared with SWNTs and $5 \mathrm{wt} \%$ of $\mathrm{Fe}_{2} \mathrm{O}_{3}$ NPs was placed between two magnets for $60 \mathrm{~min}$ and left to cure. The tensile strength increased to $106 \mathrm{MPa}$ because of the alignment of the SWNTs, as seen in Fig. 11.

\subsection{Nanofluids}

The idea of using the aggregation process in the area of nanofluids is to increase the TC of CNTs or graphene nanofluids. The aggregation of magnetic nanoparticles on the surface of CNTs or graphene makes them sensitive to the magnetic field. Then, by applying a magnetic field, the aggregated nanoparticles-CNT align with the magnetic field. This alignment improves the TC [18, 45-49]. However, in the solution form, the aggregates may fall apart because of the presence of water. 
Fig. 10 Impact of magnetic field on the alignment of the SWNTs/ $/ \mathrm{Fe}_{2} \mathrm{O}_{3}$ [32]

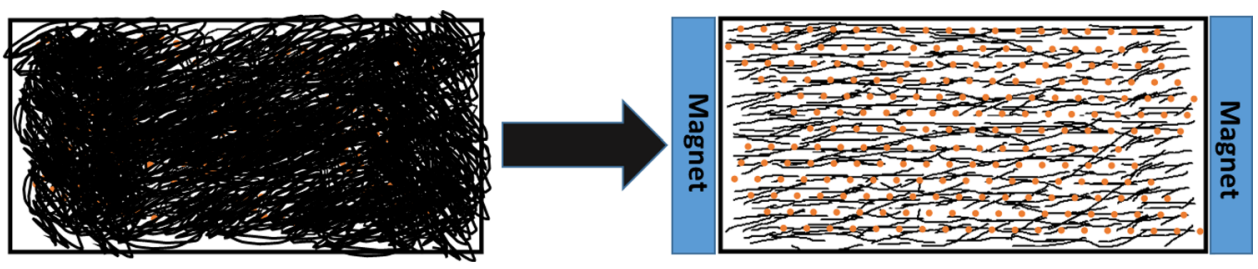

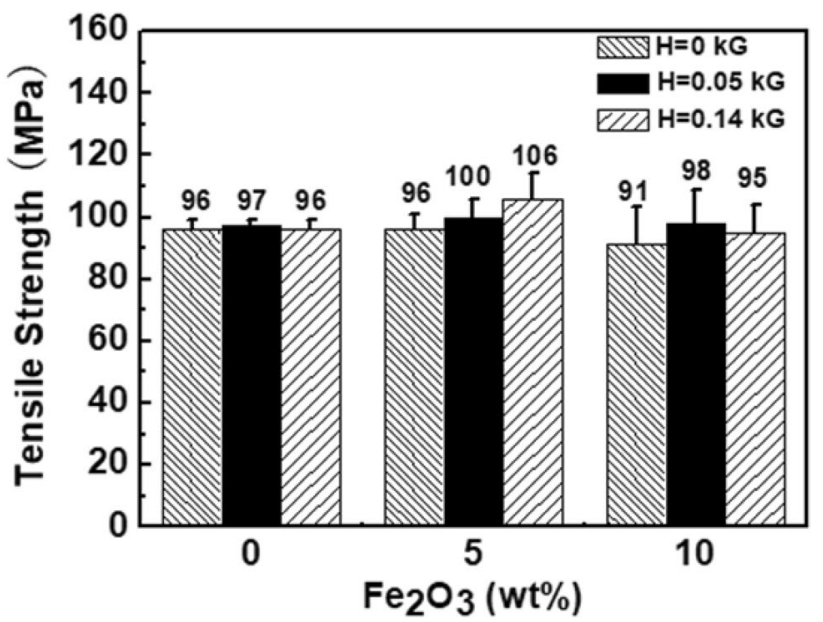

Fig. 11 Mechanical properties of SWNTs PVA composite [21]

\subsection{High Thermal Performance Materials}

Liu et al. [32] has used the same aggregation approach to fabricate magnetic sensitive SWNTs epoxy nanocomposite. Tip-sonicator and SDBS surfactant were used to ensure good dispersion of the SWNTs in aqueous solution. After $10 \mathrm{~min}$ of the dispersion process, $\mathrm{Fe}_{2} \mathrm{O}_{3}$ was added and the solution was dispersed for an additional $10 \mathrm{~min}$. Finally, the solution was vacuum-filtrated and dried in an oven at $80{ }^{\circ} \mathrm{C}$ overnight. The dried SWNTs- $\mathrm{Fe}_{2} \mathrm{O}_{3}$ was then dispersed again in an epoxy solution to fabricate the composite. Subjecting the composite to a magnetic field during the curing procedure was found to effectively align the $\mathrm{SWNTs}-\mathrm{Fe}_{2} \mathrm{O}_{3}$, which led to an enhancement in the mechanical property and the TC of the composite, as it is depicted in Figs. 12 and 13.

\section{Conclusions}

Carbon nanomaterials, including CNT, graphene, CNFs, and nanoparticles, such as $\mathrm{Fe}_{2} \mathrm{O}_{3}$ and $\mathrm{SiO}_{2}$, have been aggregated homogeneously at the nanoscale in fluids in order to form new nanosolids. These nanosolids have been shown to exhibit interesting physical properties that may be suitable in a number of applications. The detailed characterization of these nanosolids indicates that the charge attraction between the particles results in a strong, homogeneous bonding process occurring within the aqueous solution, and demonstrates the nanoscale aggregation process.

This method can not only be used for CNT, graphene, and CNF materials, but also can be extended to non-carbon nanomaterials. The nanoparticles also could be comprised of elemental metals, metalloids, metal alloys, metal sulfides, metal selenium, and/or a combination thereof. The method presented here is simple, cost-effective, and can be easily adapted to large-scale applications, once the manufacturing process has been optimized.

The results and applications presented here clearly indicate the veracity and applicability of the process/concept, and while initiated as an investigation of nanofluids it has led to the development of novel nanosolids, which have the potential for significant commercial value and considerable economic impact. Continued investigations may result in additional interesting physical properties that can be used in a number of new and emerging technologies.

Acknowledgements The author would like to thank all the students and colleagues who made this manuscript possible. Without their dedication and help, this work would have not been possible.
Fig. 12 SEM image of 0.017 wt $\%$ SWNT, 0.017 wt $\% \mathrm{Fe}_{2} \mathrm{O}_{3}$, and $0.17 \mathrm{wt} \%$ SDBS with magnetic field. a Scale bar $100 \mu \mathrm{m}$, and $\mathbf{b}$ scale bar $10 \mu \mathrm{m}$ [18]
(A)

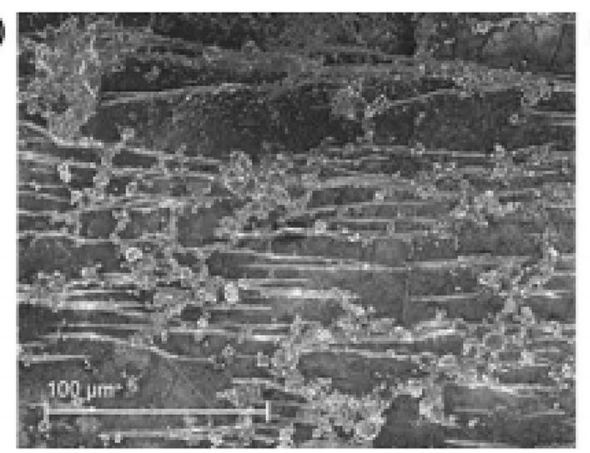

(B)

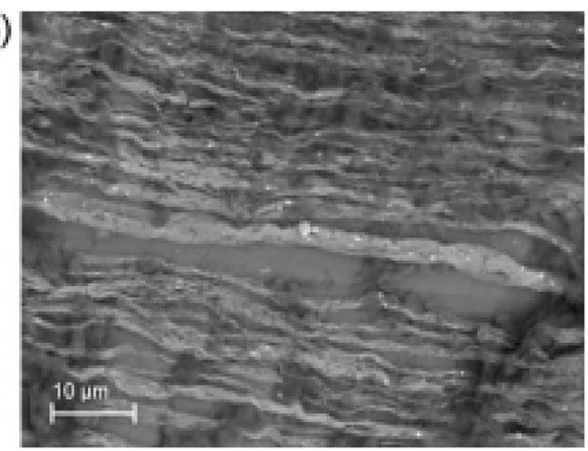


Fig. 13 a Comparison of the tensile strength of epoxy nanocomposites. b TC for different $\mathrm{wt} \%$ of SWNTs nanocomposites [32]
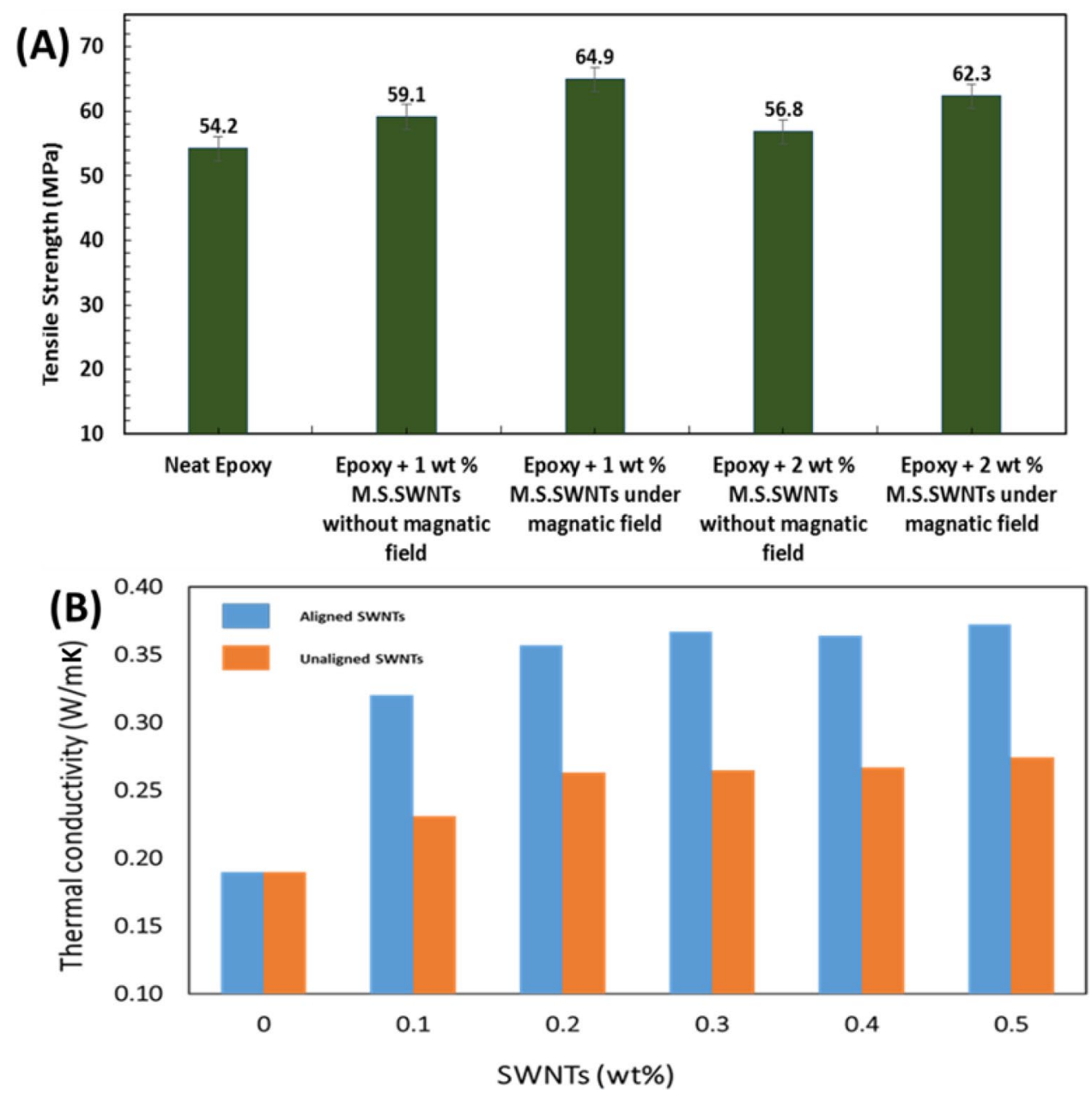

Funding This research was funded by Army Research Lab (Cooperative agreement W911NF 15-2-0034-S) and Georgia Tech IRAD funds (DE00005346).

\section{Compliance with Ethical Standards}

Conflict of interest The authors declare no conflicts of interest.

Open Access This article is licensed under a Creative Commons Attribution 4.0 International License, which permits use, sharing, adaptation, distribution and reproduction in any medium or format, as long as you give appropriate credit to the original author(s) and the source, provide a link to the Creative Commons licence, and indicate if changes were made. The images or other third party material in this article are included in the article's Creative Commons licence, unless indicated otherwise in a credit line to the material. If material is not included in the article's Creative Commons licence and your intended use is not permitted by statutory regulation or exceeds the permitted use, you will need to obtain permission directly from the copyright holder. To view a copy of this licence, visit http://creativecommons.org/licenses/by/4.0/.

\section{References}

1. Biercuk M, Llaguno MC, Radosavljevic M, Hyun J, Johnson AT, Fischer JE (2002) Carbon nanotube composites for thermal management. Appl Phys Lett 80(15):2767-2769

2. Hone J, Whitney M, Piskoti C, Zettl A (1999) Thermal conductivity of single-walled carbon nanotubes. Phys Rev B 59(4):R2514

3. Ebbesen T, Lezec H, Hiura H, Bennett J, Ghaemi H, Thio T (1996) Electrical conductivity of individual carbon nanotubes. Nature 382(6586):54-56

4. Guo X, Wang JB, Zhang HW (2006) Mechanical properties of single-walled carbon nanotubes based on higher order CauchyBorn rule. Int J Solids Struct 43(5):1276-1290. https://doi.org/ 10.1016/j.ijsolstr.2005.05.049

5. Yazdani H, Hatami K, Eftekhari M (2017) Mechanical properties of single-walled carbon nanotubes: a comprehensive molecular dynamics study. Mater Res Express 4(5):055015

6. Lee J, Rhee K, Park S (2010) The tensile and thermal properties of modified CNT-reinforced basalt/epoxy composites. Mater Sci Eng A 527(26):6838-6843

7. Paiva M, Zhou B, Fernando K, Lin Y, Kennedy J, Sun Y-P (2004) Mechanical and morphological characterization of polymer-carbon nanocomposites from functionalized carbon nanotubes. Carbon 42(14):2849-2854 
8. Ni W, Wang B, Wang H, Zhang Y (2006) Fabrication and properties of carbon nanotube and poly (vinyl alcohol) composites. J Macromol Sci Part B 45(4):659-664

9. Xuan Y, Li Q (2000) Heat transfer enhancement of nanofluids. Int J Heat Fluid Flow 21(1):58-64. https://doi.org/10.1016/ S0142-727X(99)00067-3

10. Keblinski P, Eastman JA, Cahill DG (2005) Nanofluids for thermal transport. Mater Today 8(6):36-44. https://doi.org/10.1016/ S1369-7021(05)70936-6

11. Murshed SMS, Leong KC, Yang C (2008) Investigations of thermal conductivity and viscosity of nanofluids. Int J Therm Sci 47(5):560-568. https://doi.org/10.1016/j.ijthermalsci.2007.05. 004

12. Wong KV, De Leon O (2010) Applications of nanofluids: current and future. Adv Mech Eng 2:519659

13. Krishnamurthy S, Bhattacharya P, Phelan P, Prasher R (2006) Enhanced mass transport in nanofluids. Nano Lett 6(3):419-423

14. Hong H, Wensel J, Liang F, Billups WE, Roy W (2007) Heat transfer nanofluids based on carbon nanotubes. J Thermophys Heat Transf 21(1):234-236

15. Acharya S, Alvarado J, Banerjee D, Billups W, Chen G, Cola B, Cross W, Duke E, Graham S Jr, He H (2013) Report on carbon nano material workshop: challenges and opportunities. Nanoscale Microscale Thermophys Eng 17(1):10-24

16. Rahman M, Younes H, Subramanian N, Al-Ghaferi A (2014) Optimizing the dispersion conditions of SWCNTs in aqueous solution of surfactants and organic solvents. J Nanomater 2014:1-11

17. Younes H, Christensen G, Luan X, Hong H, Smith P (2012) Effects of alignment, $\mathrm{p} \mathrm{H}$, surfactant, and solvent on heat transfer nanofluids containing $\mathrm{Fe}_{2} \mathrm{O}_{3}$ and $\mathrm{CuO}$ nanoparticles. J Appl Phys 111(6):064308

18. Hong H, Luan X, Horton M, Li C, Peterson GP (2011) Alignment of carbon nanotubes comprising magnetically sensitive metal oxides in heat transfer nanofluids. Thermochim Acta 525(1):8792. https://doi.org/10.1016/j.tca.2011.07.025

19. Christensen G, Younes H, Hong H, Peterson G (2013) Alignment of carbon nanotubes comprising magnetically sensitive metal oxides by nonionic chemical surfactants. J Nanofluids 2(1):25-28

20. Christensen G, Younes H, Hong H, Smith P (2015) Effects of solvent hydrogen bonding, viscosity, and polarity on the dispersion and alignment of nanofluids containing $\mathrm{Fe}_{2} \mathrm{O}_{3}$ nanoparticles. J Appl Phys 118(21):214302

21. Luan X, Younse H, Hong H, Peterson G (2019) Improving mechanical properties of PVA based nano composite using aligned single-wall carbon nanotubes. Mater Res Express 6(10):1050-1056

22. Neupane S, Khatiwada S, Jaye C, Fischer DA, Younes H, Hong H, Karna SP, Hirsch SG, Seifu D (2014) Single-walled carbon nanotubes coated by $\mathrm{Fe}_{2} \mathrm{O}_{3}$ nanoparticles with enhanced magnetic properties. ECS J Solid State Sci Technol 3(8):M39

23. Younes H, Christensen G, Hong H, Peterson G (2013) Alignment of different functionalized single wall carbon nanotubes using $\mathrm{Fe}_{2} \mathrm{O}_{3}$ nanoparticles under external magnetic field. J Nanofluids 2(1):4-10

24. Younes H, Christensen G, Li D, Hong H, Ghaferi AA (2015) Thermal conductivity of nanofluids: review. J Nanofluids 4(2):107-132

25. Younes H, Christensen G, Liu M, Hong H, Yang Q, Lin Z (2014) Alignment of carbon nanofibers in water and epoxy by external magnetic field. J Nanofluids 3(1):33-37

26. Younes H, Hong H (2013) Alignment of different functional single wall carbon nanotubes using $\mathrm{Fe}_{2} \mathrm{O}_{3}$ nanoparticles under external magnetic field. In: Nanotechnology 2013: electronics, devices, fabrication, MEMS, fluidics and computational, 2013. vol Chapter 5: micro \& nano fluidics. The 13th Nanotech 2013 conference, pp 393-396
27. Younes H, Rahman MM, Ni G, Al Ghaferi A, Al Rub RA, Bsoul I (2019) Investigation of magnetic properties of $\gamma-\mathrm{Fe}_{2} \mathrm{O}_{3}$ NP-decorated carbon nanostructured mats. JOM 71:3142-3150

28. Younes H, Shoaib N, Rahman MM, Al-Rub RA, Hong H, Christensen G, Chen H, Younes AB, Al Ghaferi A (2019) Thin carbon nanostructure mat with high electromagnetic interference shielding performance. Synth Met 253:48-56

29. Christensen G, Younes H, Hong H, Widener C, Hrabe RH, Wu JJ (2019) Nanofluids as media for high-capacity anodes of lithiumion battery-a review. J Nanofluids 8(4):657-670

30. Younes H, Ravaux F, El Hadri N, Zou L (2019) Nanostructuring of pseudocapacitive $\mathrm{MnFe}_{2} \mathrm{O}_{4} /$ Porous $\mathrm{rGO}$ electrodes in capacitive deionization. Electrochim Acta 306:1-8

31. Younes H, Zou L (2020) Asymmetric configuration of pseudocapacitive composite and rGO electrodes for enhanced capacitive deionization. Environ Sci Water Res Technol 6(2):392-403

32. Liu M, Younes H, Hong H, Peterson G (2019) Polymer nanocomposites with improved mechanical and thermal properties by magnetically aligned carbon nanotubes. Polymer 166:81-87

33. Christensen G, Yang J, Lou D, Hong G, Hong H, Tolle C, Widener C, Bailey C, Hrabe R, Younes H (2020) Carbon nanotubes grease with high electrical conductivity. Synth Met 268:116496

34. Christensen G, Younes H, Hong G, Lou D, Hong H, Widener C, Bailey C, Hrabe R (2020) Hydrogen bonding enhanced thermally conductive carbon nano grease. Synth Met 259:116213. https:// doi.org/10.1016/j.synthmet.2019.116213

35. Hong H, Younes H, Christensen G, Horton M, Qiang Y (2019) A rheological investigation of carbon nanotube grease. J Nanosci Nanotechnol 19(7):4046-4051

36. Hongtao L, Hongmin J, Haiping H, Younes H (2014) Tribological properties of carbon nanotube grease. Ind Lubr Tribol 66:579-583

37. Younes H, Christensen G, Groven L, Hong H, Smith P (2016) Three-dimensional (3D) percolation network structure: key to form stable carbon nano grease. J Appl Res Technol 14(6):375-382

38. Hong H, Thomas D, Waynick A, Yu W, Smith P, Roy W (2010) Carbon nanotube grease with enhanced thermal and electrical conductivities. J Nanopart Res 12(2):529-535

39. Hong H, Wensel J, Roy W (2019) Heat transfer nanolubricant and nanogrease based on carbon nanotube. ECS Trans 2(12):133-138. https://doi.org/10.1149/1.2408959

40. Hong H, Marquis FD, Waynick JA (2007) Carbon nanoparticlecontaining lubricant and grease. Google Patents

41. Hong H, Christensen G, Widener C (2018) Carbon nanotube grease and sustainable manufacturing. Proc Manuf 21:623-629. https://doi.org/10.1016/j.promfg.2018.02.164

42. Hong H, Widener CA, Christensen GL (2019) Conductive grease with enhanced thermal or electrical conductivity and reduced amount of carbon particle loading. Google Patents

43. Younes H, Christensen G, Horton M, Al Ghaferi A, Hong H, Qiang Y (2018) TC study of manufacturable nano grease: evidence of 3D network structure. Nanomanuf Metrol 1(3):148-155

44. Younes H, Al-Rub RA, Rahman MM, Dalaq A, Al Ghaferi A, Shah T (2016) Processing and property investigation of highdensity carbon nanostructured papers with superior conductive and mechanical properties. Diam Relat Mater 68:109-117

45. Hong H, Wright B, Wensel J, Jin S, Ye XR, Roy W (2007) Enhanced thermal conductivity by the magnetic field in heat transfer nanofluids containing carbon nanotube. Synth Met 157(10):437-440. https://doi.org/10.1016/j.synthmet.2007.05.009

46. Jiang Y, Opoku M, Hu Z, Liu M, Hong H, Puszynski JA, Yan $X$ (2015) Synthesis and characterization of spinel ferrite based nanofluids. J Nanofluids 4(2):133-139

47. Wright B, Thomas D, Hong H, Smith P (2013) Time dependent thermal conductivities of nanofluids containing carbon nanotubes and metal oxides. J Nanofluids 2(1):45-49 
48. Hong H, Horton M, Peterson G (2011) Aligned Ni-coated singlewalled carbon nanotubes under magnetic field for coolant applications. Three-dimensional nanoarchitectures. Springer, New York, pp 523-534

49. Horton M, Hong H, Li C, Shi B, Peterson G, Jin S (2010) Magnetic alignment of Ni-coated single wall carbon nanotubes in heat transfer nanofluids. J Appl Phys 107(10):104320

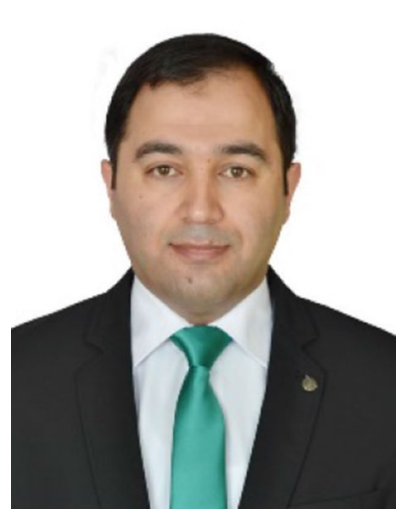

Dr. Hammad Younes is a senior Research Scientist at the Khalifa University of Science and Technology. His research focuses on the synthesis, fabrication and experimental characterization of carbon based nanomaterials (e.g. carbon nanotubes, graphene, graphene oxide, 3DrGO, MXene and carbon nanofibers), and metal/metal oxide nanoparticles in different applications such as, nanofluids, nanogrease, Capacitive Deionization, electromagnetic shielding and nanocomposites. Prior to joying Masdar in 2014, Dr. Younes has a PhD in Nanoscience and Nanoengineering from South Dakota School of Mines and Technology, Rapid City, SD, USA. Dr. Younes has more than 45 peer reviewed publications and he is a member of many scientific societies e.g. Material Research Society (MRS), American Chemical Society (ACS), North American Thermal Analysis Society (NATAS), South Dakota Academy of Science and Jordanian Chemical Society.

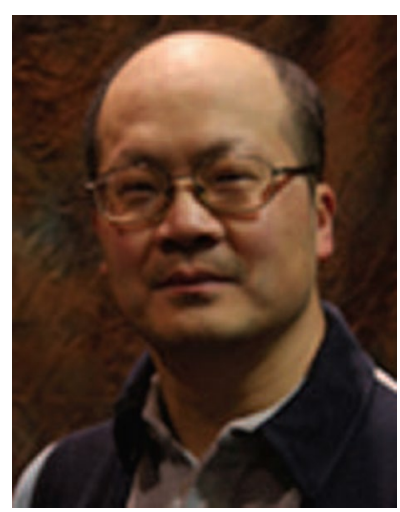

Haiping Hong is a Research Scientist IV in the Electrical Engineering department of South Dakota Mines. He was also a visiting scientist of the Georgia Institute of Technology. He received his Ph.D. from Hebrew University of Jerusalem (Israel). Prior to joining SD Mines, he worked in several silicon-valley startup companies. His recent research interests and activities include nanofluids, lubricants and greases, polymer composites, catalysis for renewable energy, batteries, chemical sensors, and carbon nanomaterials. Recently, he cofounded a startup called
Novum Nano with the intent of commercializing cutting-edge nanotechnology. Many of applications relate to this paper.

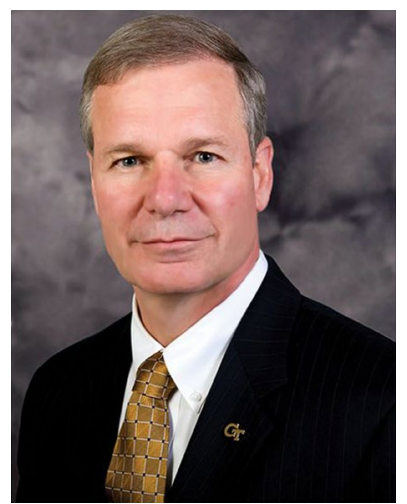

G.P. Peterson is President Emeritus and Regents Professor in the Woodruff School of Mechanical Engineering at the Georgia Institute of Technology, where he served as the 11th president from April 1, 2009 through August 31, 2019. His research interests focus on the fundamental aspects of phase-change heat transfer, including the heat transfer in reduced gravity environments, boiling from enhanced surfaces, and some of the earliest work in the area of flow and phasechange heat transfer in microchannels. More recent investigations have included fundamental applications of phase-change heat transfer to the field of biotechnology, including the insitu-treatment of cancerous tissue using hypo and hyperthermia and arresting epileptic seizures through the rapid cooling of localized tissue in the brain. 